Citation: C. Obi, D. Vergamini, F. Bartolini, G. Brunori (2020) The Impact of Changes in Regulatory and Market Environment on Sustainability of Wine Producers: A Structural Equation Model. Wine Economics and Policy 9(1): 51-61. doi: 10.36253/web-7689

Copyright: (C) 2020 C. Obi, D. Vergamini, F. Bartolini, G. Brunori. This is an open access, peer-reviewed article published by Firenze University Press (http://www.fupress.com/wep) and distributed under the terms of the Creative Commons Attribution License, which permits unrestricted use, distribution, and reproduction in any medium, provided the original author and source are credited.

Data Availability Statement: All relevant data are within the paper and its Supporting Information files.

Competing Interests: The Author(s) declare(s) no conflict of interest.
Original Research Article

\section{The Impact of Changes in Regulatory and Market Environment on Sustainability of Wine Producers: A Structural Equation Model}

\author{
Chinedu Obi ${ }^{1,2, *}$, Daniele Vergamini ${ }^{1}$, Fabio Bartolini ${ }^{1}$, Gianluca \\ BRUNORI $^{1}$ \\ ${ }^{1}$ University of Pisa, Department of Agriculture Food and Environment, Via del Borghetto \\ 80 - 56124, Pisa, Italy. ${ }^{*}$ Corresponding author \\ ${ }^{2}$ Ghent University, Department of Agriculture Economics, Coupure Links 653, Ghent Bel- \\ gium \\ E-mail: chinedutemple.obi@ugent.be, daniele.vergamini@agr.unipi.it, fabio.bartolini@ \\ unipi.it, gianluca.brunori@unipi.it
}

\begin{abstract}
We explore the farmers' perception of how different external drivers of changes in farming activities could lead to sustainability practices among wine producers. The general assumption is that regulatory and market forces can change the production strategies of wine producers, which could eventually lead to the adoption of sustainability practices. We presented the percentage sustainability practice (PSP) as a novel way of measuring sustainability. We developed a structural equation model (SEM) with 13 hypotheses to test our assumption for the wine supply chain in Tuscany (Italy). Among the market forces, we found that wine growers perceived access to credit to have a significant positive association with sustainability practices. We also found that the perception of change in regulatory instruments such as environmental regulation and Common Agriculture Policy can lead to sustainable practice if they improve access to credit. Our research provides evidence for medium-large scale wine producers, emphasising their role as carriers of innovation in the movement towards sustainable wine production.
\end{abstract}

Keywords: sustainability, wine, Structural Equation Model.

\section{INTRODUCTION}

Wine sustainability seeks to balance economic viability, social equity and environmental soundness on the whole production and processing of wine, from grapes to wine and spirits (OIV, 2016). A review of the literature on wine sustainability show a growing interest in the drivers of sustainability in the wine industry that has mainly focused on the internal drivers (Dodds et al., 2013; Flores, 2018; Gabzdylova et al., 2009; Gilinsky et al., 2016; Merli et al., 2018; Pullman et al., 2010; Santini et al., 2013; Szolnoki, 2013). Indeed, the key drivers of sustainability in wine industries can be sufficiently divided into internal and external drivers. The internal drivers are the farm-level fac- 
tors, including the managerial attitude and human capital required for the change to sustainable production. The production cost and yield impact of switching to more sustainable practices. The strategic advantages that come with sustainability labels such as improving new market penetration, competitive advantages, corporate images and reputations are farm-level internal drivers of sustainability. The external drivers that may influence the decision of whether to adopt wine sustainability are pressures from outside. These include market pressure such as consumer demand, climatic pressures such as changes in weather, and regulatory pressures and incentives such as environmental policies and credit incentives from the government.

Despite the existence of multiple relationships among the internal and external drivers and their relevance to wine sustainability, the research with evidence on how farmers perceived these drivers is still poor. Our research explores how different perception of external drivers of changes in farming activities could lead to sustainability practices among wine producers. We used a Structural Equation Model (SEM) to visualise the type of relationships existing among the drivers and their significances from the winegrowers perspective. We concentrate on external drivers because only a few researchers have quantified the drivers of wine sustainability beyond the internal factors (Santini et al., 2013). This strategy also allows a more concise evaluation of multiple variables. Our study contributes to the current literature on wine sustainability on three fronts. First, it constitutes an innovative attempt to employ an SEM in explaining the relationships of the external drivers of the sustainability practices of wine producers. Second, our study provides a unique way of measuring sustainability using the Percent Sustainability Practice (PSP). Third, we provide robust evidence, testing the model reliability and the main research hypotheses through an empirical case study of wine producers in Tuscany (Italy).

\section{THE STRUCTURAL EQUATION MODEL: CONCEPTUAL FRAMEWORK AND HYPOTHESES}

SEM is used to describe the conceptual framework for the relationship between the perceived external drivers of changes in farming practices and the level of sustainability practised by wine producers. The SEM measures unobserved latent construct by using several observed or subjective variables and imputes the relationships among them. The main advantage of the SEM is that it allows multiple and simultaneous testing of the magnitude and significance of the complex relationships between a set of variables. In Figure 1, the SEM is made up of circles which are connected by arrows. The singleheaded arrows define a causal relationship caused by the variable at the tail of the arrow, while open headed arrows indicate correlations, without a causal interpretation (Hox \& Bechger, 1999). We categorised the external drivers of sustainability into two levels: the market forces and the regulatory factors. We make a general assumption that these two groups of external forces are capable of causing a change in the production strategies adopted by wine producers, which could eventually lead to the adoption of sustainability practices (Rocchi \& Gabbai, 2013). The market forces are the changing institutional arrangements that offer advantages to wine producers when they adopt sustainability practices. For example, the provision of a credit facility, changing consumer behaviour for sustainable wines, and the changing market prices of wine (Bianchi, 2015; Santiago \& Sykuta, 2016). According to Santini et al., (2013), these three variables are considered to have a much closer influence on farmers' decision to engage in sustainability practices in the wine industry. Hence, we developed the first set of our hypotheses.

Hypothesis 1: Access to credit to influence sustainability practices positively.

Hypothesis 2: The increase in the market price of sustainable wines will influence sustainability positively.

Hypothesis 3: The change in consumer behaviour towards sustainable wine will influence sustainability practices positively.

The regulatory factors are perceived to influence sustainability practices indirectly through their effects on the variables of wine market forces. They include climate change, changes in environmental regulations, and changes in international policy. Kertész \& Madarász (2014) observed that environmental policies and climate change would probably be the major driving forces defining the direction of sustainability practices. Climate change may compel policymakers to change regional policy and local environmental regulations. For instance, in the European Union, the need to meet climate goals was the antecedent for introducing Greening in the 2013 Common Agricultural Policy (CAP) reform (Merino, 2012). The CAP could influence farmers' adoption of sustainable practices in several ways: a) by promoting investments aiming at speeding the modernisation process of the wine producers (first pillar payments). b) by ensuring a minimum environmental standard (greening and conditionality) or transition towards more sustainable farming systems (integrated or 
organic productions). c) diversifying the farming strategies with the inclusive engagement of local knowledge and territorial capital (Wine CMO reform) ${ }^{1}$. Emerging studies have shown that CAP policies have led to farmers' adoption of climate-friendly behaviour by curtailing chemical use and increasing crop diversity (Cortignani \& Dono, 2015).

Climate change may also be perceived to cause changes in wine regulations in the EU. According to Gaeta \& Corsinovi (2013), the EU has changed its wine legislation in response to climate change. Some regulations help to check farmers oenological practices and treatments to ensure quality wines (Vergamini et al., 2019). Climate changes also may influence farmers to access credit facilities. For instance, Fraga et al., (2012) observed that the increasing evidence for erratic changes in the climate called for adaptation and mitigation measures which often require additional financial resources on the wine producers. In recognition of this, the EU through the Greening policy has committed up to $30 \%$ of the $2014-2020$ budget providing non-repayable financial incentives for actions that improve climate change mitigation and adaptation measures at the farm level (Rossi et al., 2017). Climate change may also influence the market prices of wine. Relevant studies have shown that this could occur through its effect on the quantity and quality of the wine (Ashenfelter \& Storchmann, 2016).

Finally, some literature connects changes in wine regulations with changes in consumers' behaviour towards sustainable wine (Malorgio \& Grazia, 2007; Pomarici \& Vecchio, 2014; Sogari et al., 2016). These studies tend to suggest that regulations on sustainability labelling may offer quality signals to wine consumers, increasing their knowledge about sustainability and improving their willingness to pay for wine with sustainable labels (e.g. the recent spread of organic wines). More so, the price of wine is an essential driver of consumers' willingness to pay for sustainable wine (Pomarici et al., 2016; Schmit et al., 2013). Hence, we propose the next set of hypotheses which look at the interaction between the farmer perception of the regulatory forces and market forces.

Hypothesis 4: Changes in CAP policy could correlate with changes in environmental regulation.

Hypothesis 5: Changes in CAP influence wine farmers to access credit.

Hypothesis 6: Changes in CAP influence the market prices of wine.

${ }^{1}$ See the proposal for wine CMO reform http://www.krir.pl/files/analiza_reformy_rynku_wina.pdf

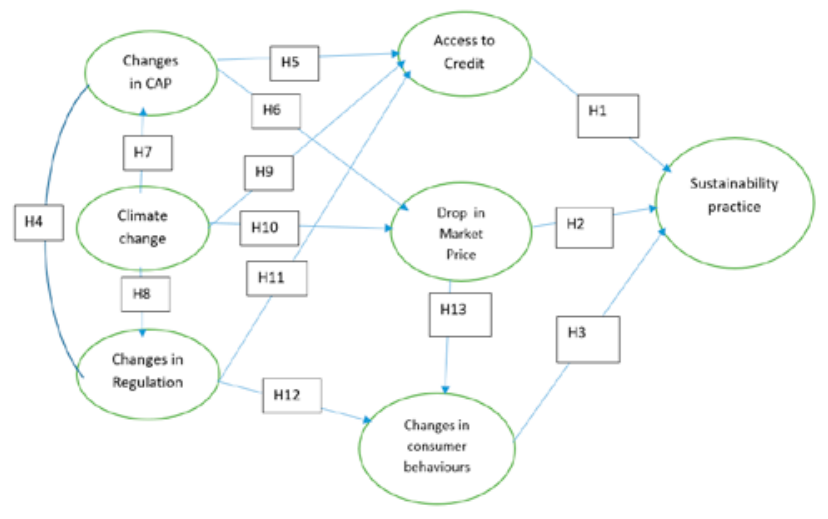

Figure 1. Hypothesized Model.

Hypothesis 7: Climate changes could influence adjustments in CAP policies.

Hypothesis 8: Climate changes influence changes in environmental regulation.

Hypothesis 9: Climate change influences access to credit.

Hypothesis 10: Climate change influences the market prices of wine.

Hypothesis 11: Changes in environmental regulation influence farmers' access to credit.

Hypothesis 12: Changes in environmental regulation influence consumer behaviours.

Hypothesis 13: Changes in market price will influence consumers' behaviour.

\section{METHOD}

\subsection{Data}

We tested the hypothesised model with a sample of Tuscan wine producers who completed the producer's survey of Sustainable Finance for Sustainable Agriculture and Fisheries - SUFISA ${ }^{2}$ - A project which investigates the wine sector in Tuscany (Italy). The SUFISA survey collected quantitative data at the farm level for Tuscan wine producers ${ }^{3}$. The survey drew respondents from a producer list collected by the Tuscany Region during the 8 th edition of an international Business-toBusiness (B2B) meeting event in Florence in 2017 (Buy-

\footnotetext{
${ }^{2}$ The purpose of SUFISA was to identify sustainable practices and policies in the agricultural, fish and food sectors that support the sustainability of primary producers in a context of multidimensional policy requirements, market uncertainties and globalisation. The project has received funds from the EU's Horizon 2020 research and innovation programme under Grant Agreement No 635577.

${ }^{3}$ For a more detailed picture of the Case study analysis (Italian National report, deliverable D2.2) here https://www.sufisa.eu/publications/
} 
Wine Meeting). Most of the participants are mediumlarge wineries from the Chianti Area, Siena and Montalcino. The questionnaire was triangulated during a stakeholders meeting and tested through six pilot phone call interviews to improve data quality. We called a sample of 110 respondents: 80 of them responded to the questions on sustainability. After eliminating one case with excessive missing data, 79 cases remaining was used in the model.

\subsection{The Respondents' Characteristics}

All the respondents are wine producers, representing vertically integrated wine farmers who participate in grape growing, wine production and marketing. The descriptive statistics of the respondents are shown in Table 1. It shows that different farm enterprises were represented in the analysis. These include individual farms (34.2\%), family farms (35.4\%), and private company farms (29.1\%). The majority of the farm owners are male (69\%), above 40 years $(63.9 \%)$, and attended at least higher secondary education (97.1\%). Considering that data was collected from wine producers who took part in a B2B meeting in Tuscany, we assume that our respondents are interested in exporting wines to other

Table 1. Respondents' Characteristics $(n=79)$.

\begin{tabular}{lcc}
\hline \multirow{2}{*}{ Item } & Definitions & $\begin{array}{c}\text { Percentage } \\
(\%)\end{array}$ \\
\hline Farm Legal Status & Individual farm & 34.2 \\
& Family farm & 35.4 \\
& Private Company & 29.1 \\
Age of producer (Years) & Public Company & 1.30 \\
& Up to 40 & 36.1 \\
& $41-50$ & 31.9 \\
Gender & $51-65$ & 26.4 \\
Education & Above 65 & 5.60 \\
& Male & 69.0 \\
Type of Wine & Female & 31.0 \\
& Lower Secondary & 2.90 \\
Total yield (hl) & Higher Secondary & 44.1 \\
& University & 52.9 \\
Grapeland (ha) & Conventional & 65.8 \\
& Organic & 34.2 \\
& Small (less than 200hl) & 26.5 \\
& Medium (from 200 to 500hl) & 25.3 \\
& Large (more than 500hl) & 48.1 \\
& Small (1 - 9) & 42.3 \\
& Medium (10 - 25) & 30.8 \\
& Large (Above 25) & 26.9 \\
\hline
\end{tabular}

countries. The survey shows that the respondents produce at a relatively medium to large scale. For instance, about $58 \%$ of the respondents have either a mediumsize grape land of 10 to 25 ha or large grape land size of more than 25 ha. In terms of wine yield, about $73 \%$ of the respondents either produce at a medium scale $(200$ to $500 \mathrm{hl}$ per annum) or a large scale (above $500 \mathrm{hl}$ per annum). These findings, therefore, represent market/ export-oriented wine producers in the Chianti Area and Siena and Montalcino in Tuscany who wishes to sell their wine in larger quantities. Following the SUFISA definition of the small primary producer, it is, however, worthwhile to note that most Tuscan wine producers are small and medium-scaled.

\subsection{Regulatory and market issues that are influencing farming strategies.}

We identified the critical variables of regulatory and market issues perceived to influence the management decision and farming strategies of wine producers. The six main variables selected during the stakeholders' interviews include changes in market price, changes in consumer behaviour, and access to credit for farm inputs for the market forces; and adverse climatic conditions and pests; changes in environmental regulations, such as pesticide regulation; and changes in the CAP policy for the regulatory forces. These variables had been identified in the literature to be among the external drivers of sustainability practices. The producer's survey asked to what extent these issues have influenced the farming strategies adopted by the wine producers. We used a 5-point Likert scale in the measurement. The Likert scale ranges from not at all (1) to strongly (5). For convenience and ease of explanation, the analysis was done by rescaling the 5-point scales to binary. The first three Likert scales: Not at all, Partly and Somewhat was recorded as No (0), and the last two, considerable and strongly were recorded as Yes (1). Hence, a Likert score of 4 or 5 shows that the underlying variable is a determinant of the choice of sustainable farming practices of the wine producer.

\subsection{Calculating Percentage Sustainability Practices of Wine producers}

The complexity associated with the sustainability framework, with its three symbiotic components (environmental, social, and economic) present difficulties in its assessment. According to Hayati (2017), there are two ways of assessing sustainability. The first is by evaluation at the component level that enables comparisons of the 
three components of sustainability, and the second is a systematic approach which was expressed as a function or aggregate of the different sustainability components. In our case, we analysed the aggregate sustainability of our respondent using the Percentage Sustainability Practice (PSP). The PSP represents the wine producers' opinions and perception of the extent to which their choice of production practices helped them maintain sustainability. Unlike Zahm et al., (2008), who used count number index, our percentage scale approach is to increase the variability of the sustainability score. It also helped to satisfy the underlying assumption of SEM, requiring that the endogenous variable must be continuous (Streiner, 2005). Instead of providing a dichotomous score for the sustainable and non-sustainable farm as done by Casas-Cazares et al., (2009), we assume that sustainability is a systemic process that should be measured in percentage level. The selected indicators for measuring sustainability are in line with the literature (Zahm et al., 2008). It includes 11 disentangled variables covering the three pillars of sustainability-i.e. environmental $(n=3)$, social $(n=4)$ and economic $(n=4)$ (Table 2). For instance, the producers were asked whether the production choice (farming strategy) they adopted help them to maintain biodiversity. A Likert scale approach was adopted to retrieve responses ranging from 1 (strongly disagree) to 5 (strongly agree). Following Bianchi, (2015), a reliability test was conducted to check the internal consistency of the indicators on the three components, and confirmatory factor analysis (CFA) was conducted for measurement validity. Furthermore, the Percent Sustainability Practice (PSP) is given as:

$P S P=\sum_{n=1}^{11}\left[\sum_{i=1}^{3} \frac{X_{i}}{n_{x}}, \sum_{j=1}^{4} \frac{Y_{j}}{n_{y}}, \sum_{k=1}^{4} \frac{Z_{k}}{n_{z}}\right] \frac{100}{T}$

where PSP $=$ Percent Sustainability Practice

$\mathrm{n}=$ Number of indicators

$\mathrm{X} \_\mathrm{i}=$ Value of the ith indicator in the Likert scale of Environment component

$Y_{-} j=$ Value of the $j$ th indicator in the Likert scale of Social component

$\mathrm{Z} \_\mathrm{k}=$ Value of the $\mathrm{kth}$ indicator in the Likert scale of Economic component

$\mathrm{T}=$ Maximum absolute value in the Likert scale

3.5 The Structural Equation Model: Assumption and Modelling

The variables of marketing and regulatory forces and the variable of PSP were combined for the final
SEM modelling. The assumption of the SEM includes that there should be no missing value, the variables are to follow a normal distribution, they must be well correlated and have satisfactory goodness of fit (Streiner, 2005). We conducted exploratory statistics to ensure that the first three assumptions were satisfied, while the goodness of fit was assessed through the SEM analysis. The SEM was performed using STATA 13.1GUI. The Maximum Likelihood Estimation method was adopted. The goodness of fit of the model was evaluated using the significant level of the Chi-square (Chi2), the value of the Root mean square error of approximation (RMSEA), Standardized Root mean square residual (SRMR), the Comparative fit index (CFI), and the Tucker-Lewis index (TLI) as suggested by Schreiber et al., (2006) and Streiner, (2005). Hence, a model with good-fit should have non-significant Chi2 test, the RMSEA and SRMR should be very close to 0 , while the CFI and TLI values should be very close to 1 .

\section{RESULTS AND DISCUSSIONS}

\subsection{The Marketing and Regulatory Drivers of Farming Strategies}

The summary of the market and regulatory drivers perceived to be influencing the farming strategies of wine producers is presented in Figure 2. Here, we considered the underlying factor as recognised essential driver of change in farming strategy if the respondent selected a score of 4 or 5 in the 5 -point Likert scale. A summation result showed that the majority (62\%) of the participants considered adverse climate conditions as a significant factor influencing their farming practice. This is followed by changes in consumer behaviours (57.7\%). Others in rank order include a severe drop in market price $(30.1 \%)$, changes in environmental regulation (21.8\%), and access to credit (20.5\%).

On the other hand, changes in CAP policy seem to play the least role in the choice of farming practices adopted by the participants (12.8\%). As expected, all six factors are important drivers of change in wineries behaviour. However, the level at which the factors influence the producers varied, with changes in the climate perceived to be the most critical driver of change in the winery industry in the study area. As previously mentioned, changes in climate conditions often trigger several series of changes both in the other regulatory and market environment that influence a decision towards the adoption of sustainability practices. Another vital factor is changes in consumer behaviour, which could motivate farmers to improve their farming practices to 


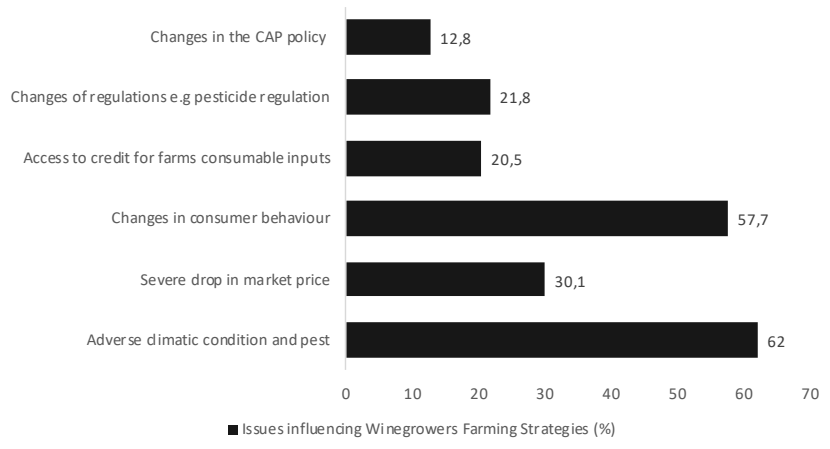

Figure 2. Drivers of Wine producers Farming Strategies.

maximise profit and remain competitive in the wine industry.

\subsection{The Percentage of Sustainability Practiced by the Wine Producers}

Using the PSP formula, sustainability was analysed as a function of the environmental, social and economic components. The description of the indicators of the components, their mean, reliability test, and coefficient of the CFA is found in Table 2. The standardised Cronbach's alpha ranged from $78 \%$ to $92 \%$, indicating a relatively high internal consistency (reliability). The results from the CFA showed that all the standardised regression on the factor loading was significant $(\mathrm{Chi} 2=283.07$, $\rho>0.000)$. This finding confirms that the indicators selected for measuring sustainability are consistent with the measurement model, providing robust support for the validity of the indicators. Generally, the mean PSP is $70.62 \%$, implying that on average, $71 \%$ of the farming strategies of the wine producers in the study area was perceived to help maintain sustainability.

\subsection{SEM: Linking Drivers of Farming Strategy with Sus- tainability Practices.}

In this section, we examined the relationship between the drivers of the farming strategy and the adoption of sustainability practices. Table 3 shows a significant correlation between changes in consumer behaviour and access to credit on PSP. Changes in consumer behaviour have a negative correlation; access to credit has a positive correlation. Although none of the regulatory factors has a significant association with PSP, our analysis showed a significant correlation between some market factors and regulatory factors. This result provides the first base to support our claim that there exist interconnectivity among the external drivers of sustainability. Moreover, almost all the constructs have skewness and kurtosis value between -2 and +2 , being a sign of univariate normality of the variables, providing a basis for testing the significance of this relationship using an SEM.

The goodness-of-fit estimation of the SEM showed a good overall fitting. The result of the SEM standardised

Table 2. Percentage Sustainability Practiced (PSP) by the Participants.

\begin{tabular}{|c|c|c|c|c|c|c|c|}
\hline & The production choice you made help you to: & Mean & S. Dev & $\beta(\mathrm{CFA})$ & Reliability & $\begin{array}{l}\text { Component } \\
\text { Mean }\end{array}$ & PSP (Total) \\
\hline \multirow[t]{3}{*}{ Environment } & Maintain biodiversity & 3.86 & 1.21 & $0.94^{* * *}$ & 0.92 & 3.72 & 70.62 \\
\hline & Maintain water quality & 3.44 & 1.31 & $0.77^{\star \star *}$ & & & \\
\hline & Maintain soil organic matter & 3.89 & 1.14 & $0.99^{* * *}$ & & & \\
\hline \multirow[t]{4}{*}{ Social } & $\begin{array}{l}\text { Create a good connection with buyers and input } \\
\text { providers }\end{array}$ & 3.94 & 0.97 & $0.82^{* * *}$ & 0.78 & 3.37 & \\
\hline & Connect with other farmers & 2.67 & 1.29 & $0.61^{* * *}$ & & & \\
\hline & $\begin{array}{l}\text { Achieve societal recognition of your farming } \\
\text { activities }\end{array}$ & 3.10 & 1.50 & $0.70^{* * *}$ & & & \\
\hline & Secure a successor & 3.77 & 0.74 & $0.55^{\star * *}$ & & & \\
\hline \multirow[t]{4}{*}{ Economic } & Maintain profitability & 3.52 & 0.95 & $0.56^{\star * *}$ & 0.81 & 3.58 & \\
\hline & Invest in the farm business & 4.03 & 0.77 & $0.75^{\star * *}$ & & & \\
\hline & $\begin{array}{l}\text { Sell the products in periods of greater difficulty } \\
\text { where prices were low }\end{array}$ & 3.41 & 0.84 & $0.65^{\star * *}$ & & & \\
\hline & Cope with changing market conditions & 3.38 & 0.76 & $0.91^{\star * *}$ & & & \\
\hline
\end{tabular}

Note: Mean is based on Likert Scale response: strongly disagree $=1$, agree $=2$, neutral $=3$, agree $=4$, strongly agree $=5$.

${ }^{* * *}$ is significant at the 0.01 level; ${ }^{* *}$ significant at the 0.05 level, ${ }^{*}$ significant at the 0.1 level.

$\mathrm{Chi}^{2}$ value $=283.07, \mathrm{p}>0.000$. 
Table 3. Correlation Statistics between Drivers of Changes and Sustainability.

\begin{tabular}{|c|c|c|c|c|c|c|c|c|c|}
\hline & PSP & I & II & III & IV & V & VI & Skewness & Kurtosis \\
\hline PSP & 1 & -0.05 & 0.04 & $-0.22^{\star \star}$ & $0.24^{\star \star}$ & 0.11 & 0.12 & 0.10 & -1.15 \\
\hline I & -0.05 & 1 & $0.38^{\star \star \star}$ & 0.11 & $0.39^{* * *}$ & $0.28^{\star *}$ & $0.30^{* * *}$ & -0.51 & -1.79 \\
\hline II & 0.04 & $0.38^{* * *}$ & 1 & 0.17 & $0.32^{\star * *}$ & $0.22^{* *}$ & $0.30^{* * *}$ & 0.74 & -1.49 \\
\hline III & $-0.22^{\star *}$ & 0.11 & 0.17 & 1 & $0.25^{\star *}$ & $0.33^{\star * *}$ & 0.18 & -0.29 & -1.97 \\
\hline IV & $0.24^{\star *}$ & $0.39^{* * *}$ & $0.32^{\star * *}$ & $0.25^{\star *}$ & 1 & $0.43^{\star * *}$ & $0.38^{* * *}$ & 1.51 & 0.28 \\
\hline V & 0.11 & $0.28^{\star *}$ & $0.22^{* *}$ & $0.31^{* * *}$ & $0.43^{* * *}$ & 1 & $0.45^{* * *}$ & 1.41 & -0.004 \\
\hline VI & 0.12 & $0.30^{* * *}$ & $0.30^{\star * *}$ & 0.18 & $0.38^{\star * *}$ & $0.45^{\star * *}$ & 1 & 2.29 & 3.32 \\
\hline
\end{tabular}

$\mathrm{I}=$ Adverse climatic conditions or pests, II = Severe drop in market prices, III = Changes in consumers behaviours, IV = Access to credit for farms consumable inputs, $\mathrm{V}=$ Change of the regulations, e.g. pesticides regulation, $\mathrm{VI}=$ Changes in the CAP. ${ }^{* *}$. Correlation is significant at the 0.01 level (2-tailed); ${ }^{*}$. at the 0.05 level; ${ }^{*}$ at the 0.10 level.

coefficient and their level of significance is presented in Table 4 and Figure. 3. Table 4 showed that the p-value of the Chi2 is 0.627; the RMSEA is 0.00, SRMR 0.039, CFI 1.00, and TLI 1.062. The final column of Table 4 shows the hypotheses that were supported by the model, while this was represented with bold lines in Figure 3. Out of the 13 hypotheses, the path coefficients of 9 were found to be correctly predicted.

\subsection{Market Drivers of Sustainability}

We consider the hypothesis of a positive relationship between the perception of market drivers of change in farming practices and sustainability adoption (Hypothesis 1-3). The results supported the hypothesis 1 by showing that having access to credit has a positive and significant association with sustainability practices $(\beta=0.312, \rho=$ 0.003 ). The model did not support hypothesis 2 , as there was no significant relationship between changes in the market price and sustainability practices $(\beta=-0.011, \rho=$ 0.916). The model also shows that changes in consumer behaviour have a significant negative relationship with farmers sustainability practice $(\beta=-0.295, \rho=0.004)$.

To discuss why access to credit has a significant positive impact on the adoption of sustainability practices, we consider the higher cost of shifting towards sustainability practice. Hence the wine producers that have adequate liquidity through credit access are more likely to a change in behaviour towards sustainability adoption (Goodhue et al., 2004; Santiago \& Sykuta, 2016).

Market prices are an economic feature that determines farmers supply, and it seems not to be a significant factor considered by farmers in the adoption of sustainable wine production in our study. The reason for this is that wine is an experience good mostly influenced by reputation, customer loyalty, and recommendation, minimally affected by price (Ashton, 2014). Without a good reputation, premium wine even if it is sustainable may not attract high demand.

Surprisingly, the result shows an inverse relationship between the producers' choice for sustainability and the attitude of consumers towards sustainability. This is probably because of the disparity in what the society or consumers attribute to be sustainability and the farmers' perception or vision of sustainability (Vergamini et al., 2019). Regional producers in Tuscany associate sustainability with a value intrinsically linked to the territory expressed by the umbrella brand "Tuscany", which consequently reflects its dynamics. If treated as an external factor, out of their control - as consumer behaviour - this is perceived as inversely related to their choice. Regardless of how the market and therefore the demand will align with this value, the producers perceive that their choices currently in the direction of greater sustainability could be upset by such a change. Consequently, hypothesis 3 partially confirms the importance of demand but also the vision of producers as actors capable of stimulating demand and therefore, a change towards greater sustainability of wine consumption.

\subsection{Regulatory Drivers of Sustainability}

On the regulatory side (Hypothesis 4 - 12), our hypothesis specifies that the changes in climate, changes in environmental regulation, and changes in CAP policy would have an indirect impact on sustainability through a change in the market environment. The result of the SEM showed that changes in CAP policy significantly correlated with changes in environmental regulation $(\beta=0.398, \rho=0.000)$, supporting Hypothesis 4 . While changes in CAP policy were found to positively influence the market price for wine $(\beta=0.205, \rho$ $=0.05)$, it did not have a significant relationship with farmers credit access $(\beta=0.175, \rho=0.103)$. Therefore, 
Table 4. Path Analysis Result from the SEM for Testing the Hypothesis.

\begin{tabular}{|c|c|c|c|c|}
\hline Item & Statement & $\beta$ & $\rho$ & Hypothesis supported? \\
\hline Hypothesis 1 & Credit access $\longrightarrow$ Sustainability & 0.312 & $0.003^{\star * *}$ & Yes \\
\hline Hypothesis 2 & Market price $\longrightarrow$ Sustainability & -0.011 & 0.916 & No \\
\hline Hypothesis 3 & Consumer behaviour $\longrightarrow$ Sustainability & -0.295 & $0.004^{* * *}$ & No \\
\hline Hypothesis 4 & $\mathrm{CAP} \leftrightarrow$ Environment regulation & 0.398 & $0.000^{* * *}$ & Yes \\
\hline Hypothesis 5 & $\mathrm{CAP} \rightarrow$ Credit access & 0.175 & 0.103 & No \\
\hline Hypothesis 6 & $\mathrm{CAP} \rightarrow$ Market price & 0.205 & $0.05^{\star}$ & Yes \\
\hline Hypothesis 7 & Climate $\rightarrow$ CAP & 0.298 & $0.003^{* * *}$ & Yes \\
\hline Hypothesis 8 & Climate $\rightarrow$ Environment regulation & 0.283 & $0.005^{\star * *}$ & Yes \\
\hline Hypothesis 9 & Climate $\rightarrow$ Credit access & 0.265 & $0.006^{\star * *}$ & Yes \\
\hline Hypothesis 10 & Climate $\rightarrow$ Market prices & 0.320 & $0.001^{* * *}$ & Yes \\
\hline Hypothesis 11 & Environmental regulation $\rightarrow$ Credit access & 0.272 & $0.010^{* *}$ & Yes \\
\hline Hypothesis 12 & Environmental regulation $\rightarrow$ Consumer behaviour & 0.308 & $0.003^{* * *}$ & Yes \\
\hline Hypothesis 13 & Market price $\rightarrow$ Consumers behaviour & 0.105 & 0.331 & No \\
\hline
\end{tabular}

${ }^{* * *}$ is significant at the 0.01 level; ${ }^{* *}$ significant at the 0.05 level, ${ }^{*}$ significant at the 0.1 level.

Hypothesis 6 was supported, but Hypothesis 5 was not. Changes in climate conditions were found to significantly influence all the paths connected to it within the model. It has a significant direct relationship with changes in CAP policy ( $\beta=0.298, \rho=0.003)$, with environmental regulation $(\beta=0.283, \rho=0.005)$, with access to credit $(\beta=0.265, \rho=0.006)$, and with changes in market price for wine $(\beta=0.320, \rho=0.001)$. Hence our model correctly predicted Hypothesis 7, 8, 9 and 10. In addition, changes in environmental regulation significantly influence wine producers' access to credit $(\beta=$ $0.271, \rho=0.010$ ), and changes in consumers behaviour ( $\beta=0.308, \rho=0.003)$, hence supporting Hypothesis 11 and 12. Finally, a change in the market price of wine was not found to influence consumers behaviours, significantly rejecting hypothesis 13 .

Generally, the results show that the regulatory drivers could impact on sustainability adoption if they lead to an improvement in access to credit. In line with the literature, our model predicts that changes in climate could be a factor influencing the introduction of instruments that promote sustainable practices in both CAP and environmental regulations. Studies have shown that introducing the greening component in the CAP policy and other environmental laws is a direct reflection of the need to manage climate change (Gaeta \& Corsinovi, 2013). Climate change also has a significant positive association with access to credit. This may indirectly lead to farmers' adoption of sustainability practices. For instance, during erratic climate change, maintain adequate agricultural practices requires the provision of financial support for wine producers. In many cases, they might rely on financial aid for adopting more restrictive and sustainable practices than mandatory ones (Cortignani \& Dono, 2015).

Our model also showed that changes in environmental regulations have an indirect influence on sustainability by improving farmers to access credit and consumer behaviour. While environmental regulation may encourage governments to provide credits to farmers, it could also enhance environmental awareness and concerns of consumers, which may result in a shift in consumer behaviour favouring a higher demand for sustainable wine (Joshi \& Rahman, 2015).

Finally, changes in the CAP policy is explicitly perceived to cause changes in market prices, but these changes do not influence farmers' adoption of sustainable practices. Surprisingly, our results also show that changes in the CAP policy have no significant direct impact on farmers' access to credit. It, therefore, seems

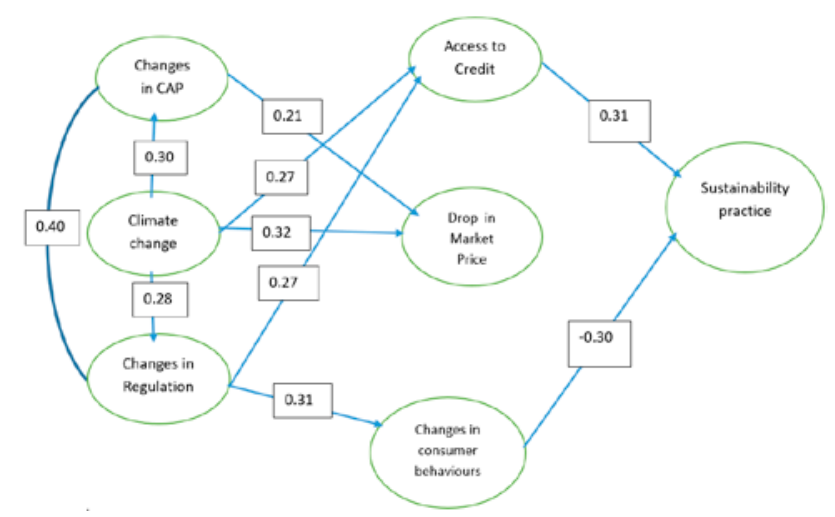

Figure 3. Result of the Path Analysis of the Hypothesized Model. 
that the CAP policy does not improve sustainability practices, yet considering that there is a significant correlation between changes in CAP policy and changes in environmental regulation, it becomes plausible to assert that the CAP policy could only influence farmers' adoption of sustainability if the policy is related to environmental issues, e.g. the greening policy. This explanation carefully means that non-greening direct payment policies may cause poor sustainability practices among wine producers.

\section{CONCLUSION AND POLICY RECOMMENDATION}

This study explored a visual path representation of the relationship of perception about the external drivers of changes in farming strategies, and how they could lead to sustainability practices for wine producers. The SEM model used in the study linked perception with stated behaviour, which is quite an innovative way of understanding the enabling factors of transition towards sustainability. A growing literature recognises perception about external drivers and signals as a critical element to explain transition towards the adoption of sustainable practices (see, for example, Dessart et al., 2019). The main findings showed that among the market factors that were hypothesised to drive sustainability, access to credit is perceived by farmers to drive wine sustainability significantly. The changes in market price and consumer behaviours do not. Our result also shows that farmers perceived that environmental regulations could significantly drive the adoption of sustainability practices if they lead to the improvement in access to credit.

However, some limitations of the study should be stressed. First, the study draws information from Tuscany medium-large scale, export-oriented wine producers. We, therefore, cannot claim that the result is representative of the Tuscan region nor could generalise the results to other areas or countries. Moreover, we adopted broad questions in our analysis, limiting our assessment to selected external drivers of sustainability. Furthermore, the model itself has a limited ability to explain or legitimise the nature of the relationship that we evidence through the analysis. However, the tool can be usefully integrated with more qualitative analysis in order to generalise some of the evidence we provided with their relevant policy implication. We refer to Vergamini et al. (2019) and the SUFISA deliverables concerning the Tuscan case study for a more in-depth qualitative and quantitative analysis of the sector.

Nonetheless, some policy implications can be drawn from the study. To influence the adoption of sustainabil- ity practices, it is essential to strengthening environmental regulations with credit incentives which could offset the additional cost associated with sustainability practices. The research results apply to medium and large wine producers, who may have adopted sustainable production to be competitive at the international level. They are crucial for innovation dissemination in the industry and may help trickle down the sustainable practices to smaller wine producers. Therefore, establishing a channel of communication between the export-oriented and small scale local producers is critical towards the achievement of sustainable wine production. We recommend that B2B meetings for wine producers should be all-inclusive and open to small farmers.

\section{ACKNOWLEDGEMENT}

We gratefully acknowledge funding from the European Union's Horizon 2020 research and innovation programme within the project SUFISA - Sustainable finance for sustainable agriculture and fisheries (Grant agreement no 635577). We also gratefully acknowledge Tuscany Region and Promofirenze for collaboration in place on the Buy Wine research.

\section{REFERENCES}

Ashenfelter, O., \& Storchmann, K. (2016). The economics of wine, weather, and climate change. Review of Environmental Economics and Policy, 10(1), 25-46. https://doi.org/10.1093/reep/rev018

Ashton, R. H. (2014). Wine as an Experience Good: Price Versus Enjoyment in Blind Tastings of Expensive and Inexpensive Wines. Journal of Wine Economics, 9(02), 171-182. https://doi.org/10.1017/jwe.2014.7

Bartolini, F., Vergamini, D. (2019) Understanding the spatial agglomeration of participation in agri-environmental schemes: The case of the Tuscany Region. Sustainability 11(10), art. no. 2753 https://doi. org/10.3390/su11102753

Bianchi, C. (2015). Consumer Brand Loyalty in the Chilean Wine Industry. Journal of Food Products Marketing, 21(4), 442-460. https://doi.org/10.1080/10454 446.2014 .885859

Casas-Cazares, R., Gonzalez-Cossio, F. V., MartinezSaldana, T., Garcia-Moya, E., \& Pena-Olvera, B. V. (2009). Sustainability and the Strategy Used in Smallholding Farming Agroecosystems in Oaxaca Valles Centrales. Agrociencia, 43(3), 319-331. https://doi. org/Article 
Cortignani, R., \& Dono, G. (2015). Simulation of the impact of greening measures in an agricultural area of southern Italy. Land Use Policy, 48, 525-533. https://doi.org/10.1016/j.landusepol.2015.06.028

Dessart, F. J., Barreiro-Hurlé, J., \& van Bavel, R. (2019). Behavioural factors affecting the adoption of sustainable farming practices: a policy-oriented review. European Review of Agricultural Economics, 46(3), 417-471.

Dodds, R., Graci, S., Ko, S., \& Walker, L. (2013). What drives environmental sustainability in the New Zealand wine industry?: An examination of driving factors and practices. International Journal of Wine Business Research, 25(3), 164-184. https://doi. org/10.1108/IJWBR-2012-0015

Flores, S. S. (2018). What is sustainability in the wine world? A cross-country analysis of wine sustainability frameworks. Journal of Cleaner Production, 172, 2301-2312. https://doi.org/10.1016/j. jclepro.2017.11.181

Fraga, H., Malheiro, A. C., Moutinho-Pereira, J., \& Santos, J. A. (2012). An overview of climate change impacts on European viticulture. Food and Energy Security. https://doi.org/10.1002/fes3.14

Gabzdylova, B., Raffensperger, J. F., \& Castka, P. (2009). Sustainability in the New Zealand wine industry: drivers, stakeholders and practices. Journal of Cleaner Production, 17(11), 992-998. https://doi. org/10.1016/j.jclepro.2009.02.015

Gaeta, D., \& Corsinovi, P. (2013). Economics, governance, and politics in the wine market: European Union Developments. Economics, Governance, and Politics in the Wine Market: European Union Developments. New York: Palgrave Macmillan US. https:// doi.org/10.1057/9781137395320

Gilinsky, A., Newton, S. K., \& Vega, R. F. (2016). Sustainability in the Global Wine Industry: Concepts and Cases. Agriculture and Agricultural Science Procedia, 8, 37-49. https://doi.org/10.1016/j. aaspro.2016.02.006

Goodhue, R. E., Heien, D. M., Lee, H., \& Sumner, D. A. (2004). Contracts and quality in the California winegrape industry. Review of Industrial Organization, 23(3-4), 267-282. https://doi.org/10.1023/ B:REIO.0000031371.03322.9e

Hayati, D. (2017). A Literature Review on Frameworks and Methods for Measuring and Monitoring Sustainable Agriculture. Technical Report n.22. Global Strategy Technical Report. Rome. Retrieved from http://gsars.org/wp-content/uploads/2017/03/TR27.03.2017-A-Literature-Review-on-Frameworksand-Methods-for-Measurin....pdf
Hox, J., \& Bechger, T. (1999). An introduction to structural equation modelling. In Family Science Review (Vol. 11, pp. 354-373). https://doi.org/10.3233/978-161499-538-8-3

Joshi, Y., \& Rahman, Z. (2015). Factors Affecting Green Purchase Behaviour and Future Research Directions. International Strategic Management Review, 3(1-2), 128-143. https://doi.org/10.1016/j.ism.2015.04.001

Kertész \& Madarász, B. (2014). Conservation Agriculture in Europe. International Soil and Water Conservation Research, 2(1), 91-96. https://doi.org/10.1016/S20956339(15)30016-2

Malorgio, G., \& Grazia, C. (2007). Quantity and quality regulation in the wine sector: The Chianti Classico appellation of origin. International Journal of Wine Business Research, 19(4), 298-310. https://doi. org/10.1108/17511060710837436

Merino, M. F. (2012). The EU Agricultural Policy Delivering on Adaptation to Climate Change. In Building resilience for adaptation to climate change in the agriculture sector: Proceedings of a Joint FAO/ OECD Workshop 23-24 April 2012. (pp. 333-336). Retrieved from http://www.fao.org/docrep/017/ i3084e/i3084e23.pdf

Merli, R., Preziosi, S. experiences in the wine sector: toward the development of an international indicators system M., \& Acampora, A. (2018). Sustainability experiences in the wine sector: toward the development of an international indicators system. Journal of Cleaner Production, 172, 3791-3805. https://doi. org/10.1016/j.jclepro.2017.06.129

OIV. (2016). General principles of sustainable vitiviniculture - environmental - social - economic and cultural aspects. Retrieved November 12, 2019, from http:// www.oiv.int/public/medias/5766/oiv-cst-518-2016-en. pdf

Pomarici, E., Amato, M., \& Vecchio, R. (2016). Environmental Friendly Wines: A Consumer Segmentation Study. Agriculture and Agricultural Science Procedia, 8, 534-541. https://doi.org/10.1016/j. aaspro.2016.02.067

Pomarici, E., \& Vecchio, R. (2014). Millennial generation attitudes to sustainable wine: An exploratory study on Italian consumers. Journal of Cleaner Production, 66, 537-545. https://doi.org/10.1016/j. jclepro.2013.10.058

Pullman, M. E., Maloni, M. J., \& Dillard, J. (2010). Sustainability practices in food supply chains: How is wine different? Journal of Wine Research, 21(1), 35-56. https://doi.org/10.1080/09571264.2010.495853

Rocchi, B., \& Gabbai, M. (2013). Territorial identity as a competitive advantage in wine marketing: a case 
study. Journal of Wine Research, 24(4), 291-310. https://doi.org/10.1080/09571264.2013.837382

Rossi, L., Gancheva, M., \& O’Brien, S. (2017). Financing climate action: opportunities and challenges for local and regional authorities. European Committee of the Regions (Vol. QG-01-17-9). https://doi. org $/ 10.2863 / 329600$

Santiago, M., \& Sykuta, M. E. (2016). Regulation and Contract Choice in the Distribution of Wine. Journal OfWine Economics, 11(2), 216-232. https://doi. org/10.1017/jwe.2015.34

Santini, C., Cavicchi, A., \& Casini, L. (2013). Sustainability in the wine industry: key questions and research trends. Agriculture and Food Economics, 1(9), 1-14.

Schmit, T. M., Rickard, B. J., \& Taber, J. (2013). Consumer valuation of environmentally friendly production practices in wines, considering asymmetric information and sensory effects. Journal of Agricultural Economics, 64(2), 483-504. https://doi. org/10.1111/1477-9552.12001

Schreiber, J. B., Stage, F. K., King, J., Nora, A., \& Barlow, E. A. (2006). Reporting structural equation modelling and confirmatory factor analysis results: A review. Journal of Educational Research. https://doi. org/10.3200/JOER.99.6.323-338

Sogari, G., Mora, C., \& Menozzi, D. (2016). Factors driving sustainable choice: the case of wine. British Food Journal, 118(3), 632-646. https://doi.org/10.1108/ BFJ-04-2015-0131

Streiner, D. (2005). Research Methods in Psychiatry. Finding Our Way: An Introduction to Path Analysis. The Canadian Journal Psychology, 50(2), 115-122. https://doi.org/10.1177/070674370505000207

Szolnoki, G. (2013). A cross-national comparison of sustainability in the wine industry. Journal of Cleaner Production, 53, 243-251. https://doi.org/10.1016/j. jclepro.2013.03.045

Vergamini, D., Bartolini, F., Prosperi, P., \& Brunori, G. (2019). Explaining regional dynamics of marketing strategies: The experience of the Tuscan wine producers. Journal of Rural Studies, 72, 136-152.

Zahm, F., Viaux, P., Vilain, L., Girardin, P., \& Mouchet, C. (2008). Assessing farm sustainability with the IDEA method - From the concept of agriculture sustainability to case studies on farms. Sustainable Development, 16(4), 271-281. https://doi.org/10.1002/sd.380 